\title{
Novel Association of Lyme disease, Age, and Atopic Dermatitis
}

Brandon T. Lee ${ }^{1,2}$, Sarah D. Galloway ${ }^{1}$, Satu Strausz ${ }^{5}$, Maia Shoham ${ }^{1}$, Paige Hansen ${ }^{1,2}$, Laughing Bear Torrez Dulgeroff ${ }^{1}$, Grace Blacker ${ }^{1}$, Ying Y. Yiu ${ }^{1}$, Paul Mansfield ${ }^{1}$, FinnGen ${ }^{9}$, Atif Saleem ${ }^{3}$, Eric Gars $^{3}$, Erin C. Sanders ${ }^{1,2}$, Irving L. Weissman ${ }^{1,4}$, Hanna M. Ollila ${ }^{5,6,7,8}$, Michal Caspi Tal ${ }^{1,2}$

${ }^{1}$ Institute for Stem Cell Biology \& Regenerative Medicine, Stanford University School of Medicine, Stanford, CA, USA

${ }^{2}$ Department of Biological Engineering, Massachusetts Institute of Technology, Cambridge, MA, USA

${ }^{3}$ Department of Pathology, Stanford University School of Medicine, Stanford, CA, USA

${ }^{4}$ Ludwig Center for Cancer Stem Cell Research \& Medicine, Stanford University School of Medicine, Stanford, CA, USA

${ }^{5}$ Institute for Molecular Medicine Finland, Helsinki Institute of Life Science, University of Helsinki, Helsinki, Finland

${ }^{6}$ Center for Genomic Medicine, Massachusetts General Hospital, Harvard Medical School, Boston, MA, USA

${ }^{7}$ Anesthesia, Critical Care, and Pain Medicine, Massachusetts General Hospital and Harvard Medical School, Boston

${ }^{8}$ The Broad Institute for Harvard and MIT, Boston, MA, USA

${ }^{9}$ FinnGen Affiliation

*Corresponding author: Michal Caspi Tal mtal@mit.edu 


\section{ETHICS APPROVAL/CONSENT TO PARTICIPATE}

Animal studies were performed at the Stanford School of Medicine Association for Assessment and Accreditation of Laboratory Animal Care International (AAALAC) accredited Rodent Animal Facility (Palo Alto, CA). All procedures and care guidelines were approved by the Stanford University Administrative Panel on Laboratory Animal Care (Protocol \#30109).

Patients and control subjects in FinnGen provided informed consent for biobank research, based on the Finnish Biobank Act. Alternatively, separate research cohorts, collected prior the Finnish Biobank Act came into effect (in September 2013) and start of FinnGen (August 2017), were collected based on study-specific consents and later transferred to the Finnish biobanks after approval by Fimea (Finnish Medicines Agency), the National Supervisory Authority for Welfare and Health. Recruitment protocols followed the biobank protocols approved by Fimea. The Coordinating Ethics Committee of the Hospital District of Helsinki and Uusimaa (HUS) statement number for the FinnGen study is Nr HUS/990/2017.

\section{ABSTRACT:}

Borrelia burgdorferi is a bacterial spirochete that can cause Lyme disease (LD) after infecting a susceptible host. Immune responses to the bacteria are highly variable and host specific. The murine substrain, $\mathrm{C} 3 \mathrm{H} / \mathrm{HeJ}$, is a frequently utilized model for LD. Interestingly, we observed dermatitis with flaky lesions of the tail skin on $\mathrm{C} 3 \mathrm{H} / \mathrm{HeJ}$ after a year of infection with $B$. burgdorferi. Female $\mathrm{C} 3 \mathrm{H} / \mathrm{HeJ}$ mice aged 6-8 weeks, 1 year, or 2 years were infected intraperitoneally with $10^{5}$ B. burgdorferi spirochetes. Mouse tails were evaluated by gross examination and histology either 2 months or 24 months post-infection. Dermatitis worsened over the course of untreated infection, with ulceration, hemorrhaging, flaking, hair loss, and dark lesions as well as spongiosis and acanthosis. These features of atopic dermatitis were present in infected mice after 1 year of age. This relationship among LD, atopic dermatitis, and host age seen in the $\mathrm{C} 3 \mathrm{H} / \mathrm{HeJ}$ mouse model is consistent with a large pool of human epidemiological data (342,499 individuals) from Finland. We identified 5,248 individuals with LD and 17,233 with atopic dermatitis in FinnGen. Retrospective analysis shows LD is associated with atopic dermatitis $\left(\mathrm{OR}=1.91[1.68-2.37], P<2 \mathrm{e}^{-16}\right)$. Repeat visits for LD complications ( 3 or more visits versus 1 visit) were associated with atopic dermatitis $(\mathrm{OR}=$ 2.19 [1.35-3.55], $P=0.0014)$ and risk of developing atopic dermatitis over time ( $\mathrm{HR}=2.26$ [1.54-3.95],$P=0.0017)$. Data from mice and humans reveal a novel relationship among LD, age, and atopic dermatitis. Through defined pathological scoring, we demonstrate that the onset of murine Lyme disease associated atopic dermatitis is exacerbated by increased host age at time of $B$. burgdorferi infection. In humans, a diagnosis of Lyme disease in FinnGen was associated with atopic dermatitis and further research is warranted to establish causation. 


\section{INTRODUCTION}

Lyme disease (LD) is the most prevalent tick-borne illness caused by infection with the spirochete Borrelia burgdorferi. LD is highly prevalent in the Northern hemisphere and especially endemic in woody regions with increased tick exposure. ${ }^{1}$ Pathogenesis of LD is classified into three stages: early localized, early disseminated, and late disseminated. ${ }^{2}$ A classic identifier which can be used to diagnose early localized LD is an erythema migrans which can develop in the first several weeks of infection. Patients may present with several different rash manifestations, including the hallmark "bulls-eye", or no rash at all. ${ }^{3,4}$ Progression to the early disseminated stage is characterized by various pathologies of the integumentary, musculoskeletal and nervous systems. ${ }^{1,5}$ If left untreated, late disseminated LD may present with cutaneous manifestations such as acrodermatitis chronica atrophicans, which may show variable atrophy and discoloration of skin. ${ }^{6}$

$\mathrm{C} 3 \mathrm{H} / \mathrm{HeJ}$ mice are commonly used as a model for LD because they develop several clinical features similar to human LD upon infection with B. burgdorferi, including carditis and arthritis. ${ }^{7}$ Compared to similar strains, $\mathrm{C} 3 \mathrm{H} / \mathrm{HeJ}$ mice exhibit chronic disease persistence with a higher degree of bacterial dissemination. ${ }^{8}$ This mouse strain developed a spontaneous mutation in the lipopolysaccharide (LPS) domain of the Toll-Like Receptor 4 (TLR4) gene. Mice of the C3H substrain typically exhibit higher disease persistence compared to other strains, whether TLR4 is functional $(\mathrm{C} 3 \mathrm{H} / \mathrm{HeN})$, or non-functional $(\mathrm{C} 3 \mathrm{H} / \mathrm{HeJ})$, indicating that TLR4 recognition may not be involved in clearance of $B$. burgdorferi. ${ }^{9}$ TLR4, which mediates pathogen sensing via recognition of LPS/endotoxin, is found in skin cells with aberrant expression in dermatitis. ${ }^{10}$ In mice challenged with the hapten, 2,4-dinitrochlorobenzene (DNCB), TLR4 knockout (KO) mice developed more severe atopic dermatitis than wild-type (WT) mice and produced high levels of inflammatory cytokines associated with Type 2 Helper T-cell $\left(\mathrm{T}_{\mathrm{H}} 2\right)$ responses. ${ }^{11}$ Interestingly, over the course of our studies on untreated long-term infection models of Lyme disease we noticed dermatitis with flaky lesions on the tail skin of $\mathrm{C} 3 \mathrm{H} / \mathrm{HeJ}$ mice after a year of infection with B. burgdorferi. However, the tail is not typically an organ of research interest and the cause of this dermatitis was unknown. Mouse studies in melanocyte pigmentation and psoriasis noted the similarity of epidermal layers between mouse tail skin and human skin, indicating the promising utility of the mouse tail as a model for pathology of the human epidermis. ${ }^{12,13}$

Atopic dermatitis (AD) is a chronic, inflammatory skin disease with usual onset occurring during childhood. ${ }^{14}$ This condition is characterized by pruritic, flaky lesions of the skin, hyperactive $\mathrm{T}_{\mathrm{H}} 2$-mediated immune responses, and relapsing episodes of skin inflammation. ${ }^{15}$ Symptoms vary 
widely across individual patients with severity dependent on several genetic and environmental factors. ${ }^{16,17}$ Skin biopsies from patients with AD typically show varying degrees of spongiosis, acanthosis, and a superficial perivascular inflammatory infiltrate. ${ }^{18}$ Spongiosis is characterized by intraepidermal and intercellular edema which may visualized as increased space between epidermal keratinocytes on Hematoxylin and Eosin (H\&E) stained histologic sections. ${ }^{18}$ Acanthosis is described as epidermal thickening. ${ }^{19}$ The perivascular inflammatory infiltrate (PVI) in atopic dermatitis is typically found in the superficial dermis and comprised of lymphocytes and histiocytes. ${ }^{20}$ Mast cells (MC) also may infiltrate the dermal layers of patients with AD, similar to individuals with inflammatory allergic responses. ${ }^{16,21}$ However, a study comparing the inflammatory response to airway irritation in different mouse strains found that $\mathrm{C} 3 \mathrm{H} / \mathrm{HeJ}$ mice do not exhibit PVI in the airway, despite expected levels of spongiosis and acanthosis. ${ }^{19}$ Furthermore, studies indicate $\mathrm{C} 3 \mathrm{H} / \mathrm{HeJ}$ mice present with PVI in the dura mater and ears, but less is known in the tail. ${ }^{22,23}$

Through histological analysis of phenotypic tails from $B$. burgdorferi-infected mice, we define a scoring method to classify severity of presumed AD based on levels of spongiosis, acanthosis, and mast cell recruitment to the skin co-occurring with gross pathologic features of the tail exterior. These scores show a significant pattern in severity of Lyme disease-associated atopic dermatitis associated with age. Furthermore, human epidemiological data from FinnGen support the findings we observe in the mouse model, showing a significant association between diagnoses of LD and AD.

\section{METHODS}

\section{Mice}

Female $\mathrm{C} 3 \mathrm{H} / \mathrm{HeJ}$ mice were provided by Jackson Laboratories (Bar Harbor, ME) at ages of 6 weeks, 8 weeks, 1 year, or 2 years $(\mathrm{n}=35)$. Experimental mice were infected with $10^{5} \mathrm{x} B$. burgdorferi spirochetes at 100 microliters $(\mu \mathrm{L})$ from a 7-day culture via intraperitoneal needle injection. All infected mice $(n=14)$ were age-matched to female, uninfected $\mathrm{C} 3 \mathrm{H} / \mathrm{HeJ}$ control mice $(\mathrm{n}=18)$ that received a vehicle control of $100 \mu \mathrm{L}$ of sterile Phosphate Buffered Saline (PBS) via intraperitoneal needle injection. Four mice expired prior to the completion of the experiment referenced in Figure 2, including uninfected 2 year $(n=2)$, uninfected 1 year $(n=1)$, and infected 1 year $(n=1)$. Humane euthanasia occurred either 2 months or 24 months post-injection for all experimental and control mice $(n=31)$ by $5 \%$ isoflurane vaporizer with active scavenging. Animal studies were performed at the Stanford School of Medicine Association for Assessment and Accreditation of Laboratory Animal Care International (AAALAC) accredited Rodent Animal Facility (Palo Alto, CA). All procedures and care 
guidelines were approved by the Stanford University Administrative Panel on Laboratory Animal Care (Protocol \#30109).

\section{Borrelia burgdorferi}

B31A3-GFP (Green Fluorescent Protein) B. burgdorferi were gifted by Dr. Jayakumar Rajadas of Stanford in $10^{7}$ cells $/ \mathrm{mL}$ aliquots and stored at $-80^{\circ}$ Celsius $(\mathrm{C}){ }^{24}$ The spirochetes were thawed and cultured in 50 milliliter $(\mathrm{mL})$ conical tubes (Corning) containing $50 \mathrm{~mL}$ Barbour-Stonner-Kelly with 4-(2-hydroxyethyl)-1-piperazineethanesulfonic acid (HEPES) buffer media (BSK-H) complete with 6\% rabbit serum (Millipore Sigma). Cultures were incubated at $37^{\circ} \mathrm{C}$ in $5 \%$ carbon dioxide for 7 days. On the same day as in vivo infection, bacterial concentration was determined by Becton Dickinson (BD) LSRFortessa Flow Cytometer and cultures were adjusted to desired working concentration using PBS.

\section{Histology}

Whole mouse tails were collected at sacrifice and fixed with 4\% paraformaldehyde (PFA) for 24 hours before they were transferred to $70 \%$ ethanol. All subsequent tissue processing was outsourced to Histowiz (Brooklyn, NY). Tails were cut to show transverse cross sections of the most cranial, caudal, or medial region. Tissue was then stained with H\&E, and in addition, Cluster of Differentiation 117 (CD117) immunohistochemistry antibody stain marker of mast cells in combination with a hematoxylin counterstain. All investigators and consulting pathologists were blinded for initial analyses to facilitate unbiased qualitative observations. Pathologists performed subsequent unblinded analysis of tail phenotypes utilizing recommendations set by the International Harmonization of Nomenclature and Diagnostic Criteria for Lesions in Rats and Mice (inHAND) Criteria. ${ }^{25}$

\section{Pathology Scoring \& Quantification}

Gross examination of the tails and microscopic analysis (Leica M205 FA) was performed to classify atopic dermatitis severity through a defined external scoring system from 0 to 5 based on increasing severity, with 5 being the most severe. Each progressively higher score includes pathologies of the previous tier. The parameters of this scale were gathered from previous studies of mouse phenotypes and initial analyses were performed blinded. See 6 external categories below : 


\begin{tabular}{|r|l|}
\hline \multicolumn{2}{|c|}{ Tail External Pathology Scoring \& Quantification } \\
\hline Score & Description \\
\hline 0 & Normal \\
\hline 1 & Areas of disorganized hair growth \\
\hline 2 & Hair loss and dark lesions \\
\hline 3 & Flaking with complete hair loss and dark lesions \\
\hline 4 & Ulceration, hemorrhaging with flaking, hair loss, and dark lesions \\
\hline 5 & Damaged distal tip of tail with ulceration, hemorrhaging, flaking, hair loss, and dark lesions \\
\hline
\end{tabular}

Histology of the tails, as previously described, was used to classify severity of clinical features of atopic dermatitis through an internal scoring system. Spongiosis was scored in a binary fashion and acanthosis of the epidermis was classified below:

\begin{tabular}{|l|l|}
\hline \multicolumn{2}{|l|}{ Tail Internal Histology Scoring \& Quantification } \\
\hline \multicolumn{2}{|l|}{ Spongiosis } \\
\hline 0 & Absent \\
\hline 1 & Present \\
\hline Acanthosis of the epidermis \\
\hline 0 & Normal \\
\hline 1 & 5 to 10 keratinocytes \\
\hline 2 & $11-14$ keratinocytes \\
\hline 3 & 15 or more keratinocytes \\
\hline
\end{tabular}

Histologic scoring utilized the cranial cross section of each tail to maintain consistency across samples. Initial analyses were performed blinded with pathologist consultation, and identified variable degrees of spongiosis and acanthosis. For each mouse, internal scores were summated and graphed against their respective external scores.

\section{FinnGen}

FinnGen is a large-scale study aiming to genotype 500,000 Finnish participants recruited from hospital samples as well as prospective and retrospective epidemiological and disease-based cohorts. This data is combined with longitudinal registries that record phenotypes and health events over the entire lifespan including the National Hospital Discharge Registry (inpatient and outpatient), Causes of Death Registry, the National Infectious Diseases Registry, Cancer 
Registry, Primary Health Care Registry (outpatient) and Drug Reimbursement Registry. This study used data from FinnGen Data Freeze 8, which includes 342,499 individuals.

We used data from the hospital inpatient, outpatient, primary outpatient, and drug reimbursement registries with International Classification of Diseases (ICD) codes for LD (ICD-10: A69.2, ICD-9: 1048A) and AD (ICD-10: L20, ICD-9: 6918 (6918X excluded), ICD-8: 691). We also retreicved information of sex, age at diagnosis, current age, and cohort.

Patients and control subjects in FinnGen provided informed consent for biobank research, based on the Finnish Biobank Act. Alternatively, separate research cohorts, collected prior the Finnish Biobank Act came into effect (in September 2013) and start of FinnGen (August 2017), were collected based on study-specific consents and later transferred to the Finnish biobanks after approval by Fimea (Finnish Medicines Agency), the National Supervisory Authority for Welfare and Health. Recruitment protocols followed the biobank protocols approved by Fimea. The Coordinating Ethics Committee of the Hospital District of Helsinki and Uusimaa (HUS) statement number for the FinnGen study is Nr HUS/990/2017.

The FinnGen study is approved by Finnish Institute for Health and Welfare (permit numbers: THL/2031/6.02.00/2017, THL/1101/5.05.00/2017, THL/341/6.02.00/2018, THL/2222/6.02.00/2018, THL/283/6.02.00/2019, THL/1721/5.05.00/2019 and THL/1524/5.05.00/2020), Digital and population data service agency (permit numbers: VRK43431/2017-3, VRK/6909/2018-3, VRK/4415/2019-3), the Social Insurance Institution (permit numbers: KELA 58/522/2017, KELA 131/522/2018, KELA 70/522/2019, KELA 98/522/2019, KELA 134/522/2019, KELA 138/522/2019, KELA 2/522/2020, KELA 16/522/2020), Findata permit numbers THL/2364/14.02/2020, THL/4055/14.06.00/2020,,THL/3433/14.06.00/2020, THL/4432/14.06/2020, THL/5189/14.06/2020, THL/5894/14.06.00/2020, THL/6619/14.06.00/2020, THL/209/14.06.00/2021, THL/688/14.06.00/2021, THL/1284/14.06.00/2021, THL/1965/14.06.00/2021, THL/5546/14.02.00/2020, THL/2658/14.06.00/2021, THL/4235/14.06.00/2021 and Statistics Finland (permit numbers: TK-53-1041-17 and TK/143/07.03.00/2020 (earlier TK-53-90-20) TK/1735/07.03.00/2021).

The Biobank Access Decisions for FinnGen samples and data utilized in FinnGen Data Freeze 8 include: THL Biobank BB2017_55, BB2017_111, BB2018_19, BB_2018_34, BB_2018_67, BB2018_71, BB2019_7, BB2019_8, BB2019_26, BB2020_1, Finnish Red Cross Blood Service Biobank 7.12.2017, Helsinki Biobank HUS/359/2017, Auria Biobank AB17-5154 and 
amendment \#1 (August 17 2020), AB20-5926 and amendment \#1 (April 23 2020), Biobank Borealis of Northern Finland_2017_1013, Biobank of Eastern Finland 1186/2018 and amendment $22 \S / 2020$, Finnish Clinical Biobank Tampere MH0004 and amendments (21.02.2020 \& 06.10.2020), Central Finland Biobank 1-2017, and Terveystalo Biobank STB 2018001 .

\section{Data Analysis}

We tested associations between $\mathrm{LD}$ and $\mathrm{AD}$ using logistic regression analysis utilizing the FinnGen data. The models were adjusted for age, sex and cohort. We calculated Cox proportional hazard model with age as the timescale using sex and cohort as covariates, and tested the model assumptions by cox.zph function. In addition, we tested survival with Kaplan-Meier estimator using a non-parametric log-rank test. We performed analyses in $\mathrm{R}$ version 4.1.0 using packages survminer and survival, and visualizing the results with survminer. A $P$ value less than 0.05 was considered statistically significant.

For mouse models, GraphPad Prism v9.1.0 was used to develop and analyze graphs, utilizing two-way ANOVA and by Šidák's multiple comparisons correction test for significance of $P<$ 0.05 .

\section{RESULTS}

\section{4-month-long chronic infection initiated in young mice leads to severe dermatitis of the tail}

In our ongoing studies using a murine model of LD, we observed that many mice which had been infected with $B$. burgdorferi, and never treated with antibiotics, developed dermatitis. This dermatitis ranged in severity, with some aged animals developing dermatitis severe enough to warrant compassionate euthanasia. In order to determine the nature and cause of the dermatitis, and how it may relate to age, we infected 8 -week-old female $\mathrm{C} 3 \mathrm{H} / \mathrm{HeJ}$ mice and closely examined them for 24 months, compared to uninfected age-matched control mice (Figure 1). Visualization of the mouse tail by light microscopy showed severe dermatitis in the infected mice. External features of the phenotypic tails included hair loss, skin flaking, hyperpigmentation, hemorrhaging, and ulceration.

Gross pathology scores of affected skin are significantly higher in aged mice with acute Lyme disease 
Aging is known to cause immune system dysfunction and increased susceptibility to disease and infection. ${ }^{26}$ To further investigate the impact of age on the onset and severity of dermatitis symptoms in the tails of mice with LD, we set up an experiment of acute Lyme disease in female $\mathrm{C} 3 \mathrm{H} / \mathrm{HeJ}$ mice of various ages at the time of infection: 6 weeks, 1 year, and 2 years (Figure 2B, $2 \mathrm{D}$, and $2 \mathrm{~F}$ ). Tails of infected mice were directly compared with age-matched uninfected controls: 6 weeks, 1 year, 2 years (Figure 2A, 2C, 2E). Two months post-infection, the mice were humanely euthanized and whole tails were evaluated by light microscopy (Figure 2). Mice infected at 6 weeks of age (Figure 2B) show a minimal difference in tail condition compared to age-matched, uninfected mice (Figure 2A). Mice infected at 1 year of age present with disorganized hair growth, varying degrees of hair loss, skin flaking, dark lesions and hemorrhaging (Figure 2D). Age-matched, 1-year-old uninfected controls show no pathology (Figure 2C). Mice infected at 2 years of age developed severe dermatitis with complete hair loss, skin flaking, dark lesions, hemorrhaging and damaged or missing distal tail tip (Figure 2F). Tails of 2-year-old age-matched, uninfected mice showed disorganized hair growth consistent with natural aging phenotypes of $\mathrm{C} 3 \mathrm{H} / \mathrm{HeJ}$ mice (Figure 2E). Surprisingly, the severe pathology of the acutely (2 month) infected 2-year-old mice (Figure $2 \mathrm{~F}$ ) is grossly indistinguishable from the chronically (24 month) infected mice (Figure 1B).

External pathology was quantified for all cohorts and analyzed using two-way ANOVA followed by Šidák's multiple comparisons test $(P<0.005)$. Mice acutely infected at 6 weeks of age had minimal statistically significant differences in tail pathology to their uninfected controls $(P$ $<0.05$, LS mean difference $=1.00,95 \%$ CI $[0.08154,1.918])$. Substantially greater statistical difference is seen in 1- and 2-year-old mice compared to their respective age-matched uninfected controls $(P<0.0005$, LS mean $=3.25,95 \%$ CI $[2.223,4.277]$ and $P<0.0005$, LS mean $=4.10$, 95\% CI 3.885, 5.315]) (Figure 2G). Tail pathology external scoring and quantification parameters are detailed in the methods. Score values for tail pathologies in individual mice are shown in Supplementary Table 1.

\section{Features of atopic dermatitis found in histopathology of affected skin from mice acutely infected with $B$. burgdorferi show increased severity with advanced age}

Human atopic dermatitis is commonly a clinical diagnosis and biopsies are only rarely performed in the evaluation. ${ }^{14}$ Similar to human histopathology, murine AD presents with varying levels of acanthosis, spongiosis, and perivascular inflammation. ${ }^{19}$ Another commonly observed feature of human atopic dermatitis, which is observed in the B. burgdorferi-infected mice of this study, is post-inflammatory hyperpigmentation of the skin, which is pigmentation that occurs after resolution of inflammatory skin eruptions. ${ }^{27}$ Gross pathology identified the development of age-dependent dermatitis on the tails of $\mathrm{C} 3 \mathrm{H} / \mathrm{HeJ}$ mice acutely infected ( 2 months) with $B$. 
burgdorferi in 3 different age groups (6 week, 1 year, 2 years). Tails from these mice were then processed for histology.

Transverse cross sections from the caudal, medial, and distal tail regions from these age-macthed uninfected and infected mice were stained with H\&E for evaluation (Supplementary Figure 1). Epidermal regions of the tail were closely evaluated for features of dermatitis (Figure 3). Mice infected with B. burgdorferi at 6 weeks of age showed lack of histopathologic findings (Figure 3B). Mice infected at 1 year of age developed acanthosis, spongiosis and mild thickening of the stratum corneum, as visualized by sections of the tail skin (Figure 3D). Mice infected at 2 years of age showed the most significant pathology with more severe acanthosis accompanied by elongated rete ridges, spongiosis and hyperkeratosis (Figure 3F). All mice infected at 1 and 2 years of age also showed loss of hair follicles and post-inflammatory hyperpigmentation consistent with observations from gross examination.

The assigned scores for both external and internal pathology were then compared via heat map which revealed strong associations (Supplementary Figure 2). For each mouse, internal scores of acanthosis and spongiosis were summated and graphed against their respective external score (Supplementary Figure 2A). Individual mice with severe external features of AD additionally had congruent histopathologic findings. Likewise, uninfected mice had low scores for both external and internal AD pathology.

\section{Mast cells localize to atopic dermatitis lesions consistent with age-dependent severity in mice with acute Lyme disease}

Mast cells (MC) are key mediators of the $\mathrm{T}_{\mathrm{H}} 2$ immune response and are classically involved with allergy and IgE-mediated inflammation. ${ }^{28}$ Several studies have implicated MC involvement in AD pathogenesis, including IgE-mediated sensitization to environmental allergens as a typical feature of human AD. ${ }^{21}$ Further, B. burgdorferi spirochetes are capable of inducing mast cell degranulation. ${ }^{29}$ We therefore investigated if the age-dependent pattern of AD severity seen in $\mathrm{C} 3 \mathrm{H} / \mathrm{HeJ}$ mice with LD may be correlated with MC localization to these lesions.

Tail sections from mice infected with B. burgdorferi at ages of 6 weeks, 1 year, and 2 years along with their aged matched uninfected controls were stained antibodies against CD117, a receptor tyrosine kinase and mast cell marker (Figure 4A-F). During analysis, mast cells were classified by cellular shape and CD117 stain intensity. All positively identified MC within the dermis of a single tail section were quantified for all cohorts and analyzed using two-way ANOVA followed by Šidák's multiple comparisons test $(\mathrm{P}<0.005)$. 
Interestingly, both acutely infected 1- and 2-year old mice groups had substantial MC localization to the AD lesions (Figure 4G). Mice infected at 1 year of age $(P=0.005$, LS mean $=$ $16,95 \%$ CI $6.715,25.29])$ or 2 years of age $(P=0.0002$, LS mean $=20.72,95 \%$ CI $[10.17$, 31.28]) had significantly more MCs in the dermal layer of the tail than their age-matched, uninfected controls. In contrast, mice infected at 6 weeks of age had no significant difference in $\mathrm{MC}$ count compared to their respective uninfected controls $(P=0.74$, LS mean $=2.667,95 \% \mathrm{CI}$ $[-6.619,11.95])$.

\section{Lyme disease associates with atopic dermatitis in humans}

Recent large scale cohorts have provided means to explore epidemiological correlates leveraging on electronic health records. Using electronic health records comprising 342,499 individuals in FinnGen we identified 5,248 individuals with LD; 444 individuals from hospital inpatient, 1,317 individuals from hospital outpatient and 3,487 individuals from primary outpatient registries. We identified 17,233 individuals with AD; 3,063 individuals from hospital inpatient, 7,841 individuals from hospital outpatient, 5,796 individuals from primary outpatient and 533 individuals from drug reimbursement registries with 298 individuals with both LD and AD, and the majority of individuals being disease free for $\operatorname{LD}$ or $\mathrm{AD}(\mathrm{n}=320,316)$ (Figure 5A).

Overall, we identified 298 prevalent cases that had diagnosis for both AD and LD, and 85 incident cases that had $\mathrm{AD}$ diagnosis after $\mathrm{LD}$ diagnosis. AD was more frequent in individuals with LD (5.7\% in individuals with LD vs. 5.0\% in individuals without LD) (Figure 5A).

The association between $\mathrm{LD}$ and $\mathrm{AD}$ was statistically significant $(\mathrm{OR}=1.91[1.68-2.37], P<$ 2e-16). We estimated the severity of LD infection by dividing the number of diagnoses into two categories; 3 or more LD diagnoses vs. 1 LD diagnosis. We excluded individuals who had AD diagnosis prior to $\mathrm{LD}$ diagnosis ( $\mathrm{N}$ remaining $=4,373$ individuals with $\mathrm{LD}, 75$ participants with LD and AD diagnosis). First, we calculated logistic regression model and discovered that LD with more than 3 diagnoses was significantly associated with increased risk for AD $(\mathrm{OR}=2.19[1.35-3.55], P=0.0014)$. In addition, we estimated temporal effect by Cox-proportional hazard model using age as the timescale showing corresponding result $(\mathrm{HR}=2.26[1.54-3.95]$, $P=0.0017)$. Finally, we calculated Kaplan Meier estimates demonstrating that survival probability differed significantly between groups 3 or more LD diagnoses vs. 1 LD diagnosis. Consequently, we show that patients in the $1 \mathrm{LD}$ diagnosis group had a higher AD free survival percentage compared to individuals in the 3 or more LD group $(\mathrm{P}=4.0 \mathrm{e}-5)$ (Figure $5 \mathrm{~B})$. 


\section{DISCUSSION}

Classic phenotypes of Lyme disease in humans after acute B. burgdorferi infection include skin manifestations of various clinical phenotypes such as the erythema migrans, but this varies significantly across humans. New onset of chronic dermatologic conditions after LD have not been well investigated. The $\mathrm{C} 3 \mathrm{H} / \mathrm{HeJ}$ mouse model is frequently used in LD research because it presents with both arthritis and carditis. However, we observed that female $\mathrm{C} 3 \mathrm{H} / \mathrm{HeJ}$ mice chronically infected with $B$. burgdorferi often developed severe dermatitis of the tail. Since the mouse tail skin shares more similarity with human skin as compared to areas of skin with dense fur, we focused on this tissue to investigate this dermatitis further. Due to the absence of noticeable dermatitis in younger infected mice, we investigated whether dermatitis in older infected mice was primarily driven by the length of infection or the age of the host animal at the time of infection.

We developed a numeric scoring system to assess the external pathology and internal histology of murine skin. Higher scores were associated with more severe pathology. Both internal and external scoring increasingly worsened with age and we found a strong correlation between increased age and AD severity of the tail among B. burgdorferi-infected mice. Interestingly, internal and external scores of both acutely ( 2 months) infected 2 -year-old mice, and mice who had been chronically ( 24 months) infected since 8 weeks old, both resulted in severe pathologic changes of hair loss, skin flaking, hyperpigmentation, and ulceration. The youngest mice (6 weeks old) did not develop features of AD within the 2-month observation period before euthanasia. While natural aging does impact hair growth and tissue quality in uninfected controls, the infection consistently and significantly amplified the extent of AD lesions on the tails of mice with LD. These lesions were also associated with increased mast cell infiltration to the tail dermis.

Given the dermatologic findings we observed in both acutely and chronically infected aged mice, we were curious to see if Lyme disease was also associated with atopic dermatitis in humans through analysis of clinically diagnosed LD and AD patients from FinnGen in 342,499 individuals. We found a significant association between LD and AD. Among people with LD, there was a higher prevalence of AD than among the general population. Approximately $90 \%$ of individuals who are diagnosed with acute LD recover without complications, and therefore we further divided the individuals with LD in FinnGen into a subset who had one medical visit due to LD and a subset who had three or more visits. We observed an association with AD and the number of visits due to LD, which may reflect disease severity. Consequently, those individuals who have several healthcare visits due to LD may have a higher risk for AD than individuals with only one visit. 
Increased age can have damaging effects on immune system regulation and host defenses, while also raising the risk for inflammatory conditions. ${ }^{28}$ Age-related defects in critical mechanisms such as production of pro-inflammatory cytokines (TNF- $\alpha$ and IFN- $\gamma$ ) and terminal differentiation of keratinocytes can induce differential phenotypes of the epidermis. ${ }^{29}$ Mast cells are a major effector cell type implicated in pathogenesis of human AD through the release of proinflammatory mediators and IgE-mediated sensitization of environmental allergens. ${ }^{21}$ Utilizing mouse models, mast cells have also been implicated in other age-related pathologic mechanisms, such as damage to lung endothelial tissue due to MC-mediated neutrophil migration. ${ }^{30}$ Existing literature exploring the role of $\mathrm{MC}$ in LD is limited; however, evaluation of gerbils infected with $B$. burgdorferi showed significant histopathologic changes, including MC infiltration of the extracellular matrix surrounding major organs. ${ }^{31}$ As LD is an illness primarily characterized by inflammation of the joints, infection with B. burgdorferi could contribute to mast cell dysregulation and possibly lead to a higher risk of developing inflammatory diseases such as AD.

Aged female $\mathrm{C} 3 \mathrm{H} / \mathrm{HeJ}$ mice with acute and chronic LD present with $\mathrm{AD}$ of the tail that is indistinguishable by gross evaluation and histology; a finding that was not observed in uninfected age-matched controls or in young mice. This phenotype establishes a significant association between age of host with $\mathrm{LD}$ and onset of $\mathrm{AD}$. We provide a numeric scale to quantify severity of AD, both internally and externally. This work also supports utilization of the $\mathrm{C} 3 \mathrm{H} / \mathrm{HeJ}$ mouse model in further study of lyme-disease associated AD. The corroborating human data from FinnGen also bolsters the validity of a novel relationship between age, Lyme disease, and atopic dermatitis.

\section{LIMITATIONS}

Importantly, the mouse tails in this study which presented with $\mathrm{AD}$ were not evaluated for presence of B. burgdorferi spirochetes, although expected, as B. burgdorferi is frequently found in the tail tissue of infected wild caught mice. ${ }^{32}$

Symptoms of hair loss, ulceration, and tail tip disfiguration could be exacerbated by mouse self-mutilation induced from pruritus, or itch. Mice used for this study were not monitored for behavior, so frequency and severity of self-scratching or biting cannot be determined. When external tail pathology was observed, it was present in all mice of a single cage, suggesting that the pathology was not due to aggressive behaviors between individual mice.

Our histological analyses of the whole tail sections find two of the three key features of atopic dermatitis: spongiosis and acanthosis. As PVI is not commonly observed in the $\mathrm{C} 3 \mathrm{H} / \mathrm{HeJ}$ mouse 
strain, the presence of spongiosis and acanthosis are used to determine atopic dermatitis even in the absence of PVI.

The human disease association data from FinnGen may reflect more severe pathology since FinnGen is enriched for hospital level diagnoses. The enrichment for hospital level diagnoses may result in larger effect sizes than what may be observed in more benign pathology or in outpatient only data. Furthermore, the number of LD diagnoses have increased substantially during the last ten years. In the sample population found in FinnGen, the median age of patients diagnosed with $\mathrm{AD}$ was 32.9 years, and the median age of the LD population was 63.9 years. The recent shift in frequency of diagnoses of LD and the earlier age of diagnosis in AD may affect our power to examine any temporal associations between LD and AD that we conduct in this patient population. Some of these limitations can be addressed in the future with larger data sets and with longer follow-up.

\section{FIGURES AND FIGURE LEGENDS}

\section{Uninfected}

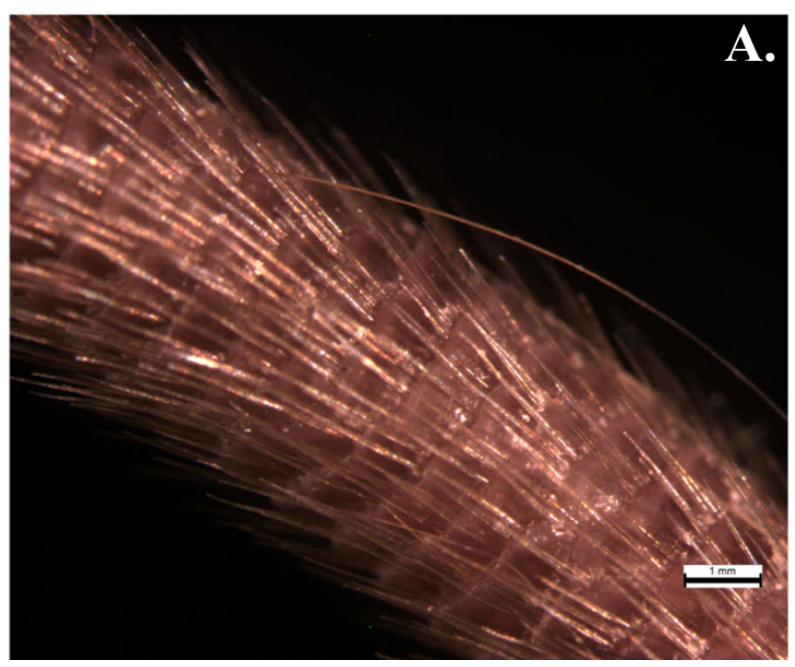

Infected

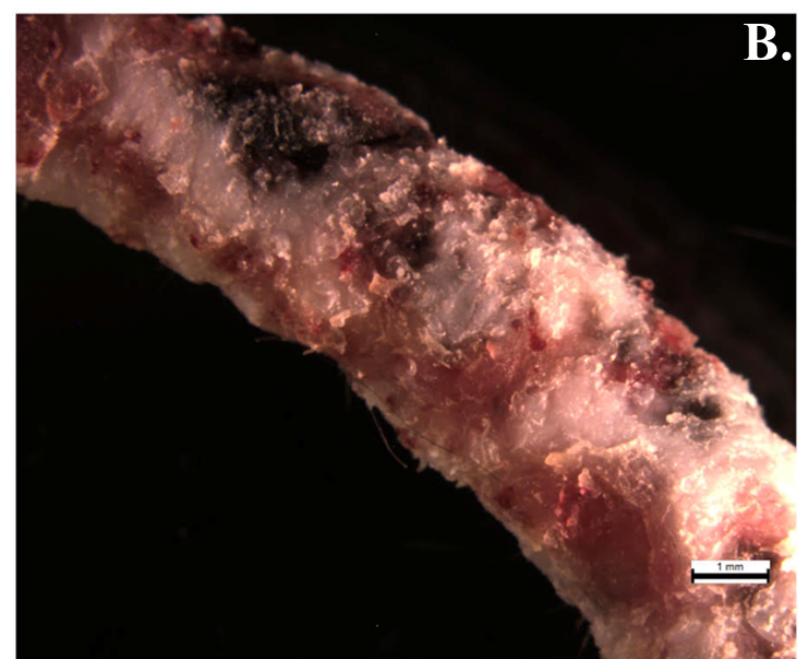

Figure 1. Chronic B. burgdorferi infection results in severe tail pathology.

Uninfected female $\mathrm{C} 3 \mathrm{H} / \mathrm{HeJ}$ control mice $(\mathrm{n}=4)(\mathrm{A})$ were compared to age-matched mice infected with $B$. burgdorferi at 8 weeks of age and sustained a chronic infection for 24 months (n =3) (B). Upon euthanasia, tails were analyzed by light microscopy and evaluated for external pathology. Scale bars are equivalent to $1 \mathrm{~mm}$. 

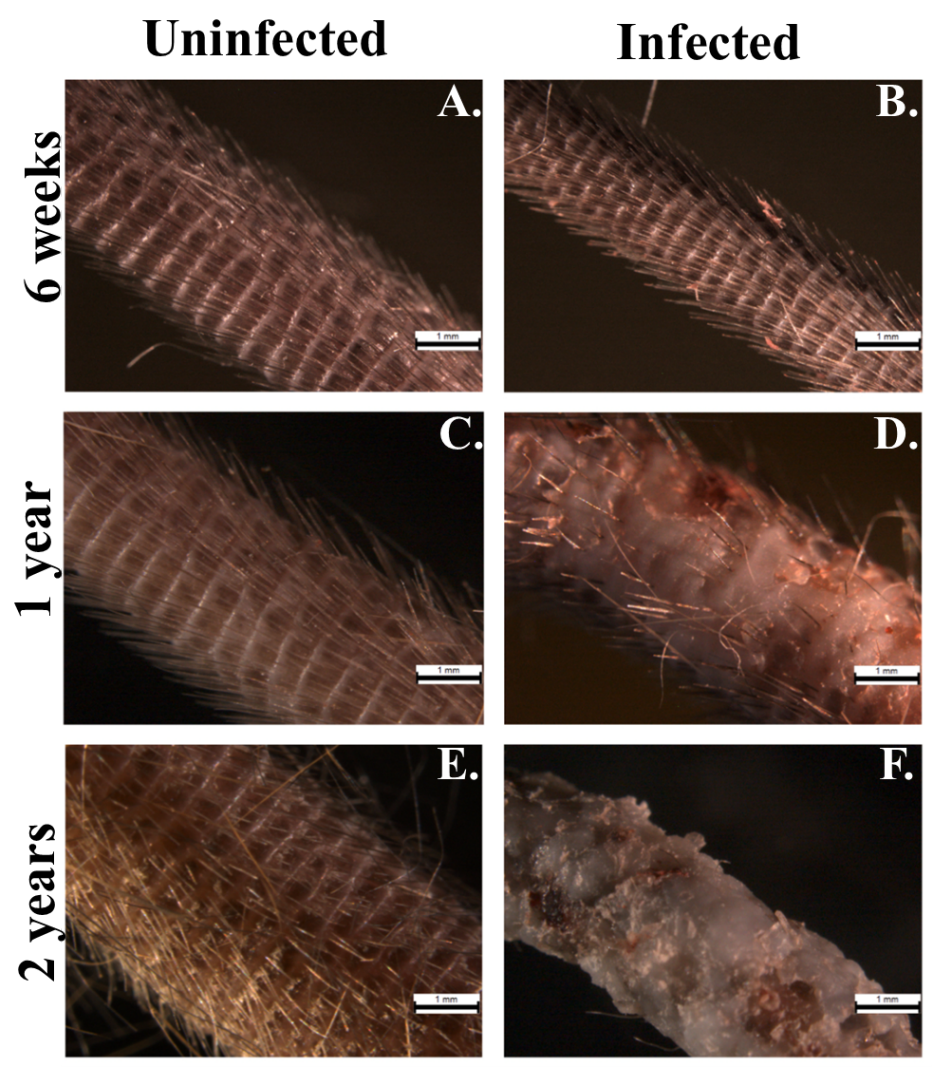

\section{Infected}

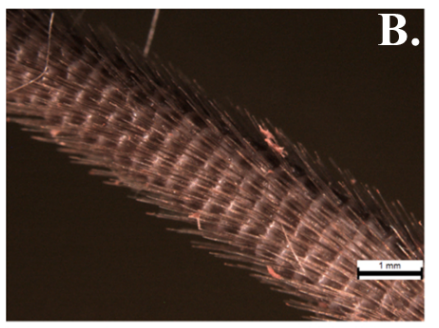

G.

\section{Gross Pathology Scoring by} Age at Time of Infection

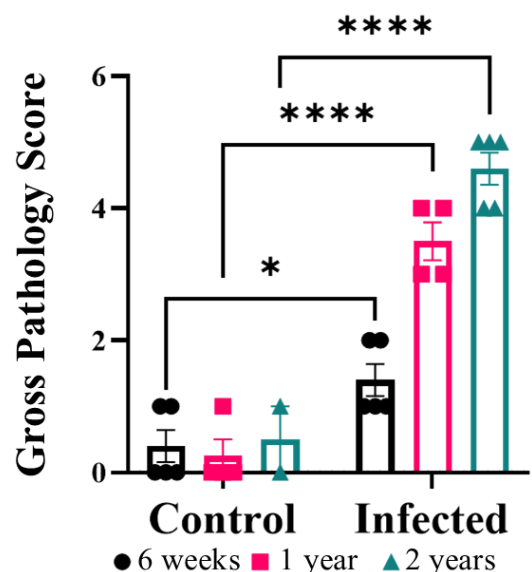

Figure 2. Gross tail pathology in mice with acute Lyme disease significantly increases with age. Uninfected female $\mathrm{C} 3 \mathrm{H} / \mathrm{HeJ}$ control mice aged 6 weeks $(n=5)(A), 1$ year $(n=4)(C)$, or 2 years $(\mathrm{n}=2)(\mathrm{E})$ were compared to mice infected with $B$. burgdorferi at equivalent ages of 6 weeks $(n=5)(B), 1$ year $(n=4)(D)$, or 2 years $(n=5)(F)$. Images of tails were taken 2 months post-infection and severity of dermal pathology was evaluated and scored. Assigned scores were then analyzed using two-way ANOVA followed by Šidák's multiple comparisons test $(* P<0.05$, $* * * * P<0.0005)(\mathrm{G})$. Scale bars are equivalent to $1 \mathrm{~mm}$. 

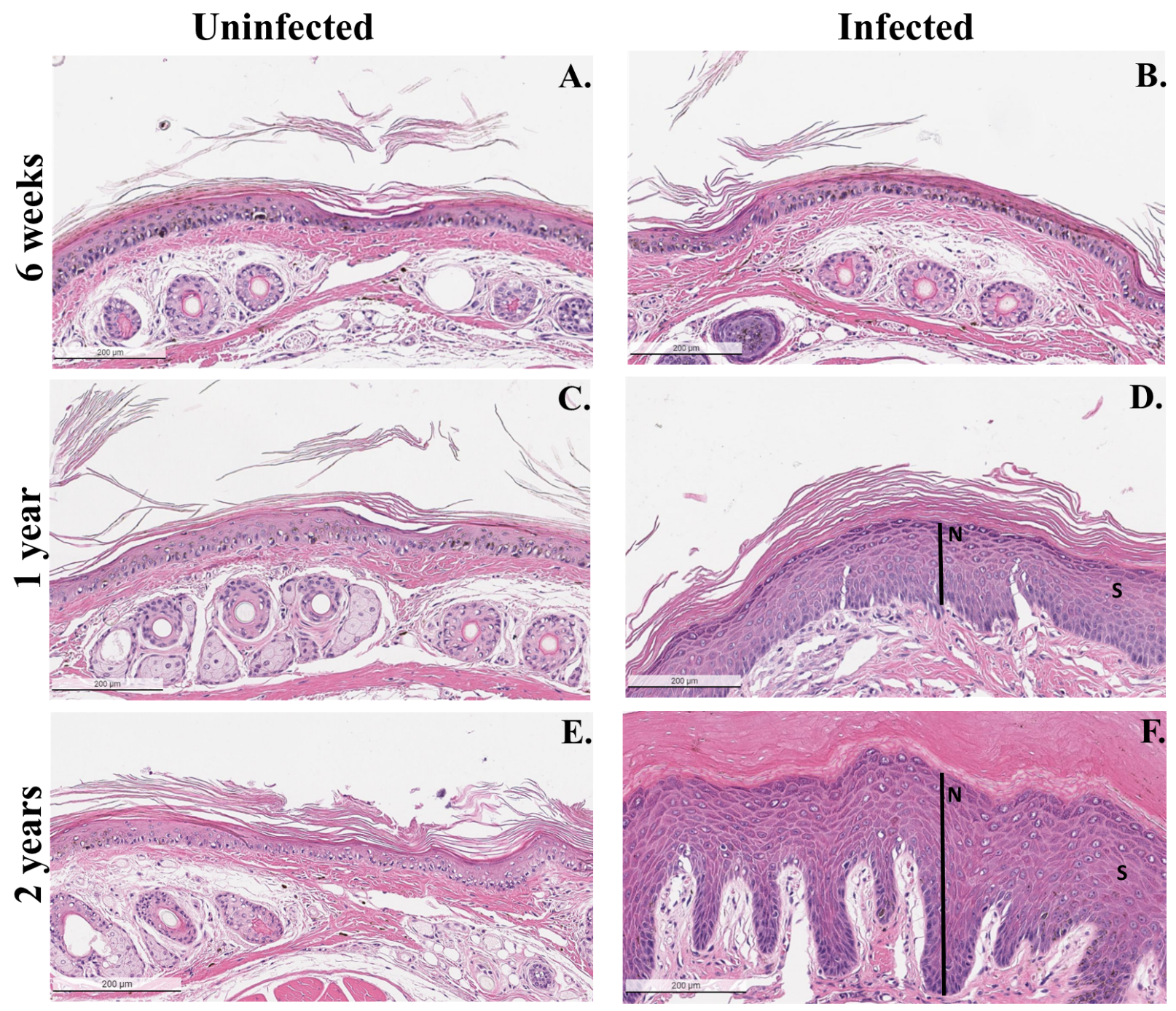

\section{Figure 3: Tail histopathology of mice with acute $B$. burgdorferi infection reveal features of atopic dermatitis that worsen with age.}

Representative images of transverse cross sections of the mouse tail stained with H\&E.

Uninfected female C3H/HeJ control mice aged 6 weeks $(n=5)(A), 1$ year $(n=4)(C)$, or 2 years $(\mathrm{n}=2)(\mathrm{E})$ were compared to mice infected with B. burgdorferi at equivalent ages of 6 weeks (n $=5)(B), 1$ year $(n=4)(D)$, or 2 years $(n=5)(F)$ Mice were humanely euthanized at 2 months post-infection and all tails were collected for histology. Presence of spongiosis is exemplified by an "S", and acanthosis of the epidermis is indicated by a black line labeled "N". All images are at $10 \mathrm{X}$ magnification, and scale bars are equivalent to $200 \mu \mathrm{m}$. 

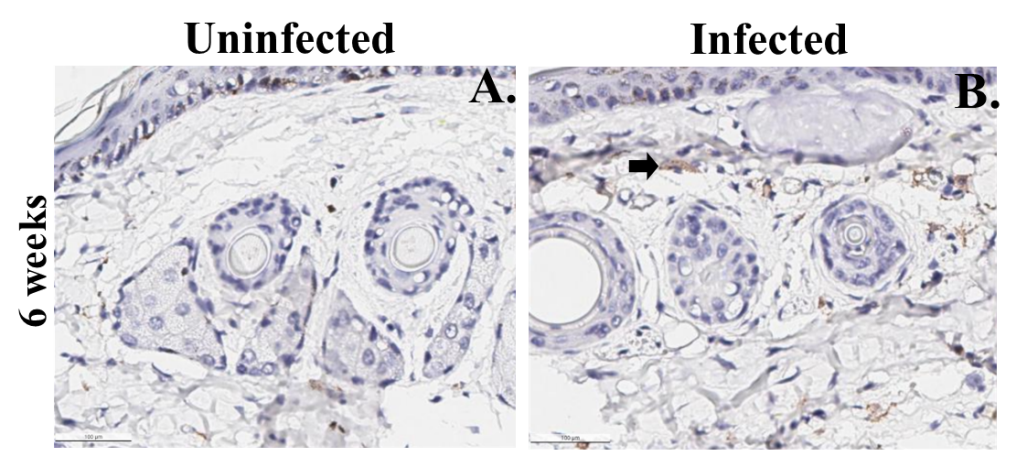

\section{G. \\ Mast Cells in Dermis}
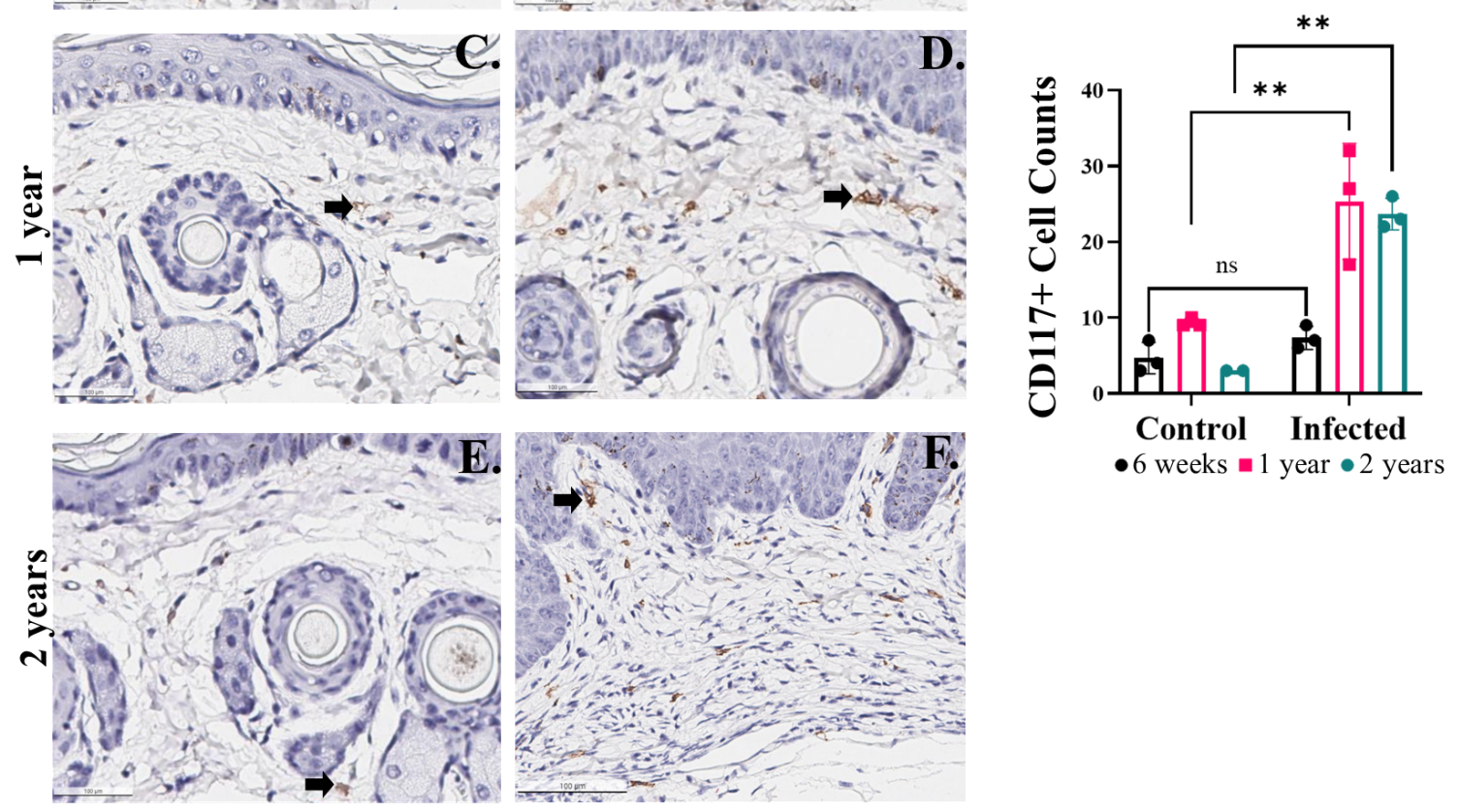

Figure 4: Mast cells localize to atopic dermatitis lesions consistent with age-dependent severity in mice with acute Lyme disease.

Representative images of transverse cross sections of the mouse tail stained for CD117 (brown) with a hematoxylin counterstain (purple). Uninfected female $\mathrm{C} 3 \mathrm{H} / \mathrm{HeJ}$ control mice aged 6 weeks $(\mathrm{n}=3)(\mathrm{A}), 1$ year $(\mathrm{n}=3)(\mathrm{C})$, or 2 years $(\mathrm{n}=2)(\mathrm{E})$ were compared to mice infected with B. burgdorferi at equivalent ages of 6 weeks $(n=3)(B), 1$ year $(n=3)(D)$, or 2 years $(n=3)$ (F). Mice were humanely euthanized at 2 months post-infection and a select number of tails were collected for histology to determine mast cell prevalence by CD117 staining. Black arrows indicate a representative mast cell in each image. The total mast cell count is shown by age and condition using two-way ANOVA followed by Šidák's multiple comparisons test (ns $\mathrm{p}>0.05$, $* * P<0.005)(\mathrm{G})$. Scale bars are equivalent to $100 \mu \mathrm{m}$. 
A.

\begin{tabular}{|l|r|r|}
\hline Total FinnGen Individuals & $\mathbf{3 4 2 , 4 9 9}$ & $\mathbf{1 0 0} \%$ \\
\hline Lyme Disease & $\mathbf{5 , 2 4 8}$ & $\mathbf{1 . 5}$ \\
\hline Inpatient & 444 & 8.5 \\
\hline Outpatient & 1,317 & 25.1 \\
\hline Primary Outpatient & & \\
Registries & 3,487 & 66.4 \\
\hline Non-LD & 337,251 & 98.5 \\
\hline Atopic Dermatitis & $\mathbf{1 7 , 2 3 3}$ & $\mathbf{5 . 0}$ \\
\hline Inpatient & 3,063 & 17.8 \\
\hline Outpatient & 7,841 & 45.5 \\
\hline Primary Outpatient & & \\
\hline Registries & 5,796 & 33.6 \\
\hline Drug reimbursement & 533 & 3.1 \\
\hline Non-AD & 325,266 & 95.0 \\
\hline Both LD and AD & $\mathbf{2 9 8}$ & $\mathbf{0 . 1}$ \\
\hline Non LD or AD & 320,316 & 93.5 \\
\hline
\end{tabular}

Prevalence of AD in Total FinnGen $\quad 5.0 \%$

Prevalence of $\mathrm{AD}$ in $\mathrm{LD}$ population $\quad 5.7 \%$

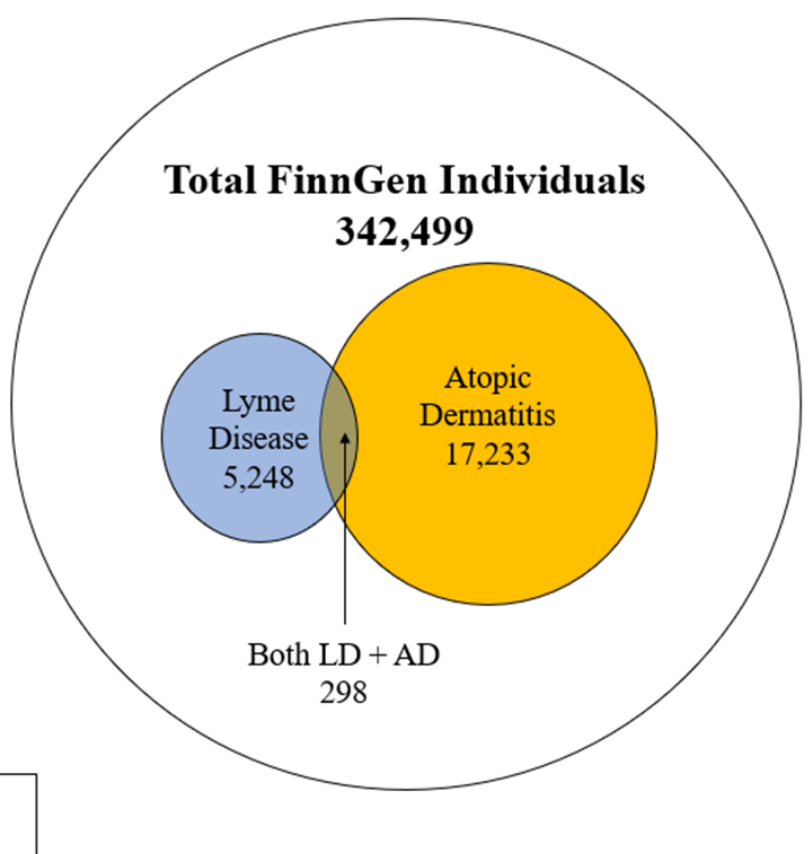

B. Association of Lyme Disease and Atopic Dermatitis

$$
1.0
$$

$0.9-$
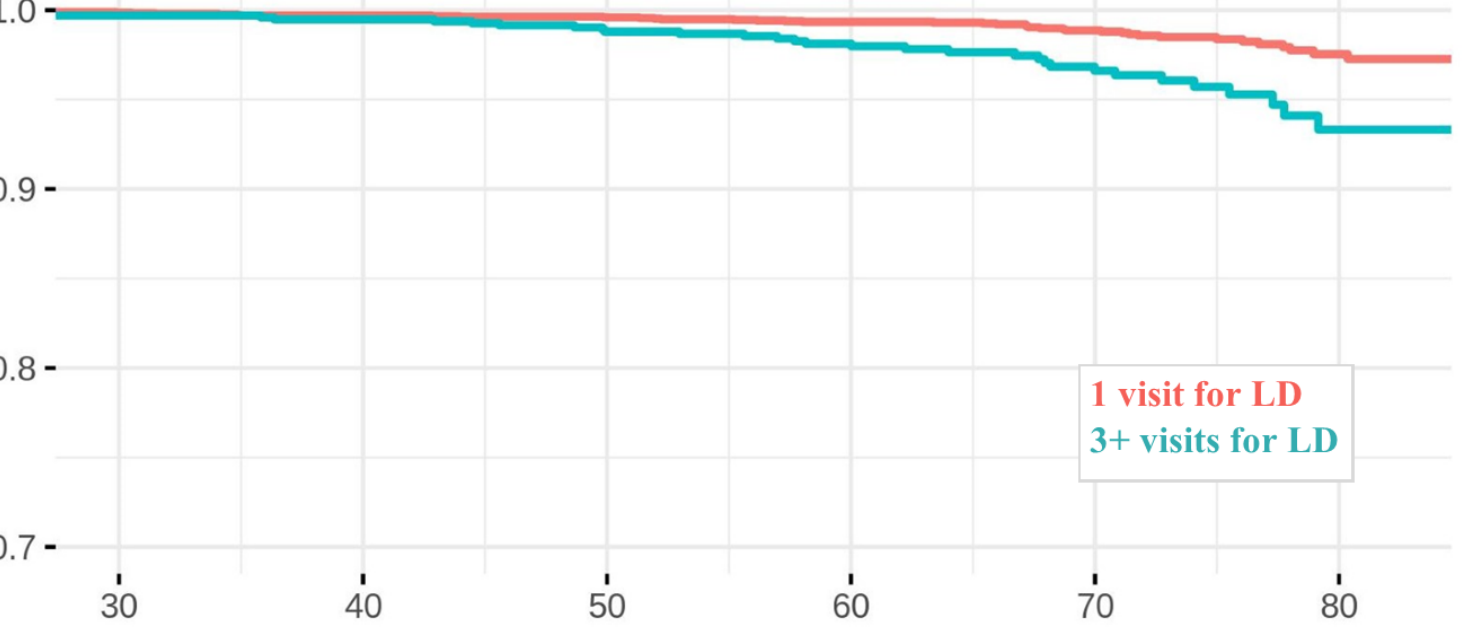

Age in years

Figure 5: Association of Lyme disease (LD) with atopic dermatitis (AD) in FinnGen .

(A) Prevalence of LD and AD in FinnGen. (B) Kaplan-Meier survival analysis in incident AD in individuals with 1 diagnosis for LD (blue), or at least 3 LD diagnoses (red). All individuals $(\mathrm{N}=$ $75)$ have at least one LD diagnosis prior to onset of $\mathrm{AD}\left(\log \operatorname{rank} P=4.0 \mathrm{e}^{-5}\right)$. 


\begin{tabular}{|c|c|}
\hline \multicolumn{2}{|c|}{ ABBREVIATIONS } \\
\hline $\mathrm{AD}$ & Atopic Dermatitis \\
\hline ACA & Acrodermatitis Chronica Atrophicans \\
\hline AAALAC & $\begin{array}{l}\text { Association for Assessment and Accreditation of Laboratory Animal } \\
\text { Care International }\end{array}$ \\
\hline B. burgdorferi & Borrelia burgdorferi \\
\hline $\mathrm{BD}$ & Becton Dickinson \\
\hline BSK-H & $\begin{array}{l}\text { Barbour-Stonner-Kelly with 4-(2-hydroxyethyl)-1- } \\
\text { piperazineethanesulfonic acid (HEPES) buffer }\end{array}$ \\
\hline $\mathrm{C}$ & Celcius \\
\hline CD117 & Cluster of Differentiation 117 \\
\hline CDC & Centers for Disease Control and Prevention \\
\hline DEJ & Dermal-Epidermal Junction \\
\hline DNCB & 2,4-dinitrochlorobenzene \\
\hline GFP & Green Fluorescent Protein \\
\hline $\mathrm{H} \& \mathrm{E}$ & Hematoxylin and Eosin \\
\hline ICD & International Classification of Diseases \\
\hline IL & Interleukin \\
\hline inHAND & $\begin{array}{l}\text { International Harmonization of Nomenclature and Diagnostic Criteria } \\
\text { for Lesions in Rats and Mice }\end{array}$ \\
\hline $\mathrm{KO}$ & Knock Out \\
\hline LD & Lyme Disease \\
\hline $\mathrm{MC}$ & Mast Cell \\
\hline $\mathrm{mL}$ & Milliliters \\
\hline PBS & Phosphate Buffered Saline \\
\hline PFA & Paraformaldehyde \\
\hline PRR & Pattern Recognition Receptor \\
\hline PVI & Perivascular Infiltrate \\
\hline $\mathrm{T}_{\mathrm{H}} 2$ & Type 2 Helper T-cell \\
\hline TLR & Toll-Like Receptor \\
\hline$\mu \mathrm{L}$ & Microliters \\
\hline US & United States \\
\hline WT & Wild-type \\
\hline
\end{tabular}

\section{CONFLICT OF INTEREST}

None of the authors have any conflicts of research regarding the research presented in this manuscript.

\section{FUNDING}


Research reported in this publication was supported by the Fairbairn family foundation; the Younger family foundation; the Robert J. Kleberg, Jr., and Helen C. Kleberg Foundation; Bay Area Lyme Foundation; the Virginia and D. K. Ludwig Fund for Cancer Research; M.C.T. and Y.Y.Y. were supported by Stanford Immunology training grant 5T32AI007290, and M.C.T. was also supported by the NIH NRSA 1 F32 AI124558-01 award. S.D.G. was supported by the California Institute for Regenerative Medicine Bridges 2.0 Grant EDUC2-08397. L.B.T.D. was supported by a Stanford Diversifying Academia Recruiting Excellence Fellowship.

FinnGen is funded by two grants from Business Finland (HUS 4685/31/2016 and UH 4386/31/2016) and the following industry partners: AbbVie Inc., AstraZeneca UK Ltd, Biogen MA Inc., Bristol Myers Squibb (and Celgene Corporation \& Celgene International II Sàrl), Genentech Inc., Merck Sharp \& Dohme Corp, Pfizer Inc., GlaxoSmithKline Intellectual Property Development Ltd., Sanofi US Services Inc., Maze Therapeutics Inc., Janssen Biotech Inc, Novartis AG, and Boehringer Ingelheim. Following biobanks are acknowledged for delivering biobank samples to FinnGen: Auria Biobank (www.auria.fi/biopankki), THL Biobank (www.thl.fi/biobank), Helsinki Biobank (www.helsinginbiopankki.fi), Biobank Borealis of Northern Finland

(https://www.ppshp.fi/Tutkimus-ja-opetus/Biopankki/Pages/Biobank-Borealis-briefly-in-English. aspx), Finnish Clinical Biobank Tampere

(www.tays.fi/en-US/Research_and_development/Finnish_Clinical_Biobank_Tampere), Biobank of Eastern Finland (www.ita-suomenbiopankki.fi/en), Central Finland Biobank (www.ksshp.fi/fi-FI/Potilaalle/Biopankki), Finnish Red Cross Blood Service Biobank (www.veripalvelu.fi/verenluovutus/biopankkitoiminta) and Terveystalo Biobank (www.terveystalo.com/fi/Yritystietoa/Terveystalo-Biopankki/Biopankki/). All Finnish Biobanks are members of BBMRI.fi infrastructure (www.bbmri.fi). Finnish Biobank Cooperative -FINBB (https://finbb.fi/) is the coordinator of BBMRI-ERIC operations in Finland. The Finnish biobank data can be accessed through the Fingenious ${ }^{\circledR}$ services (https://site.fingenious.fi/en/) managed by FINBB. The funders had no role in study design, data collection and analysis, decision to publish, or preparation of the manuscript.

\section{AUTHORS' CONTRIBUTIONS}

B.T.L. and M.S. carried out initial infections and observations. S.G. and G.B. contributed to subsequent infections and observations. B.T.L., L.B.T.D., P.M., P.H., and Y.Y.Y.conducted endpoint tissue procurement. S.G. prepared samples for histopathology and contributed to histopathology analysis. A.S. and E.G. conducted primary analysis of histopathology and murine diagnosis. The FinnGen Project was utilized for human epidemiological data that was studied and analyzed by S.S. and H.M.O.. S.G. wrote the manuscript with B.T.L. Subsequent manuscript contributions and edits were made by M.C.T., E.S., S.S., H.M.O., S.G., BT.L., P.H., G.B. and AS. B.T.L., S.S., and H.M.O. created figures with contributions by M.C.T., S.G., G.B., E.S., and 
P.H. M.C.T. and I.L.W. supervised all experiments and writing of the manuscript. All authors read and approved the final manuscript.

\section{ACKNOWLEDGEMENTS}

The authors wish to thank members of the Weissman Lab at the Institute for Stem Cell Biology \& Regenerative Medicine at Stanford University School of Medicine and Histowiz for their processing of our histological samples. We want to acknowledge the participants and investigators of the FinnGen study. 


\begin{tabular}{|c|c|c|c|c|c|c|}
\hline & \multicolumn{2}{|c|}{6 weeks } & \multicolumn{2}{|c|}{1 year } & \multicolumn{2}{|c|}{2 years } \\
\hline & $\begin{array}{l}\text { Control } \\
(n=5)\end{array}$ & $\begin{array}{l}\text { Infected } \\
(n=5)\end{array}$ & $\begin{array}{l}\text { Control } \\
(n=4)\end{array}$ & $\begin{array}{l}\text { Infected } \\
(n=4)\end{array}$ & $\begin{array}{l}\text { Control } \\
(n=2)\end{array}$ & $\begin{array}{l}\text { Infected } \\
(n=5)\end{array}$ \\
\hline $\begin{array}{l}\text { Disorganized hair } \\
\text { growth }\end{array}$ & $0 / 5$ & $4 / 5$ & $0 / 4$ & $4 / 4$ & $1 / 2$ & $5 / 5$ \\
\hline Hyperpigmentation & $0 / 5$ & $0 / 5$ & $0 / 4$ & $4 / 4$ & $0 / 2$ & $5 / 5$ \\
\hline Hair loss & $0 / 5$ & $0 / 5$ & $0 / 4$ & $3 / 4$ & $1 / 2$ & $5 / 5$ \\
\hline Flaking & $0 / 5$ & $0 / 5$ & $0 / 4$ & $4 / 4$ & $0 / 2$ & $5 / 5$ \\
\hline Hemorrhage & $0 / 5$ & $0 / 5$ & $0 / 4$ & $2 / 4$ & $0 / 2$ & $4 / 5$ \\
\hline Damaged tip of tail & $0 / 5$ & $0 / 5$ & $0 / 4$ & $0 / 4$ & $0 / 2$ & $3 / 5$ \\
\hline Ulceration & $0 / 5$ & $1 / 5$ & $0 / 4$ & $3 / 4$ & $0 / 2$ & $5 / 5$ \\
\hline
\end{tabular}

\begin{tabular}{|c|c|c|c|c|c|c|}
\hline & \multicolumn{2}{|c|}{6 weeks } & \multicolumn{2}{|c|}{1 year } & \multicolumn{2}{|c|}{2 years } \\
\hline & $\begin{array}{l}\text { Control } \\
(\mathrm{n}=5)\end{array}$ & $\begin{array}{l}\text { Infected } \\
(\mathrm{n}=\mathbf{5})\end{array}$ & $\begin{array}{l}\text { Control } \\
(n=4)\end{array}$ & $\begin{array}{l}\text { Infected } \\
(n=4)\end{array}$ & $\begin{array}{l}\text { Control } \\
(n=2)\end{array}$ & $\begin{array}{l}\text { Infected } \\
(n=5)\end{array}$ \\
\hline Acanthosis & $0 / 5$ & $0 / 5$ & $0 / 4$ & $4 / 4$ & $0 / 2$ & $5 / 5$ \\
\hline $\begin{array}{l}\text { Flaking stratum } \\
\text { corneum }\end{array}$ & $0 / 5$ & $0 / 5$ & $0 / 4$ & $4 / 4$ & $1 / 2$ & $5 / 5$ \\
\hline $\begin{array}{l}\text { Loss of dermal } \\
\text { hair follicles }\end{array}$ & $0 / 5$ & $0 / 5$ & $0 / 4$ & $3 / 4$ & $0 / 2$ & $5 / 5$ \\
\hline Spongiosis & $0 / 5$ & $0 / 5$ & $0 / 4$ & $3 / 4$ & $0 / 2$ & $5 / 5$ \\
\hline
\end{tabular}

Supplementary Table 1: Pathologic scoring quantification of tails in mice with acute Lyme disease.

(A) External pathology. Each condition observed on the mouse tail and used in external scoring is reported as present or absent per individual mouse. Top row indicates age of mice at time of infection with B. burgdorferi or injection with vehicle control. (B) Internal Histopathology. Each condition observed in the mouse tail and used for internal scoring is reported as present or absent per individual mouse. Top row indicates age of mice at time of infection with B. burgdorferi or injection with vehicle control. 

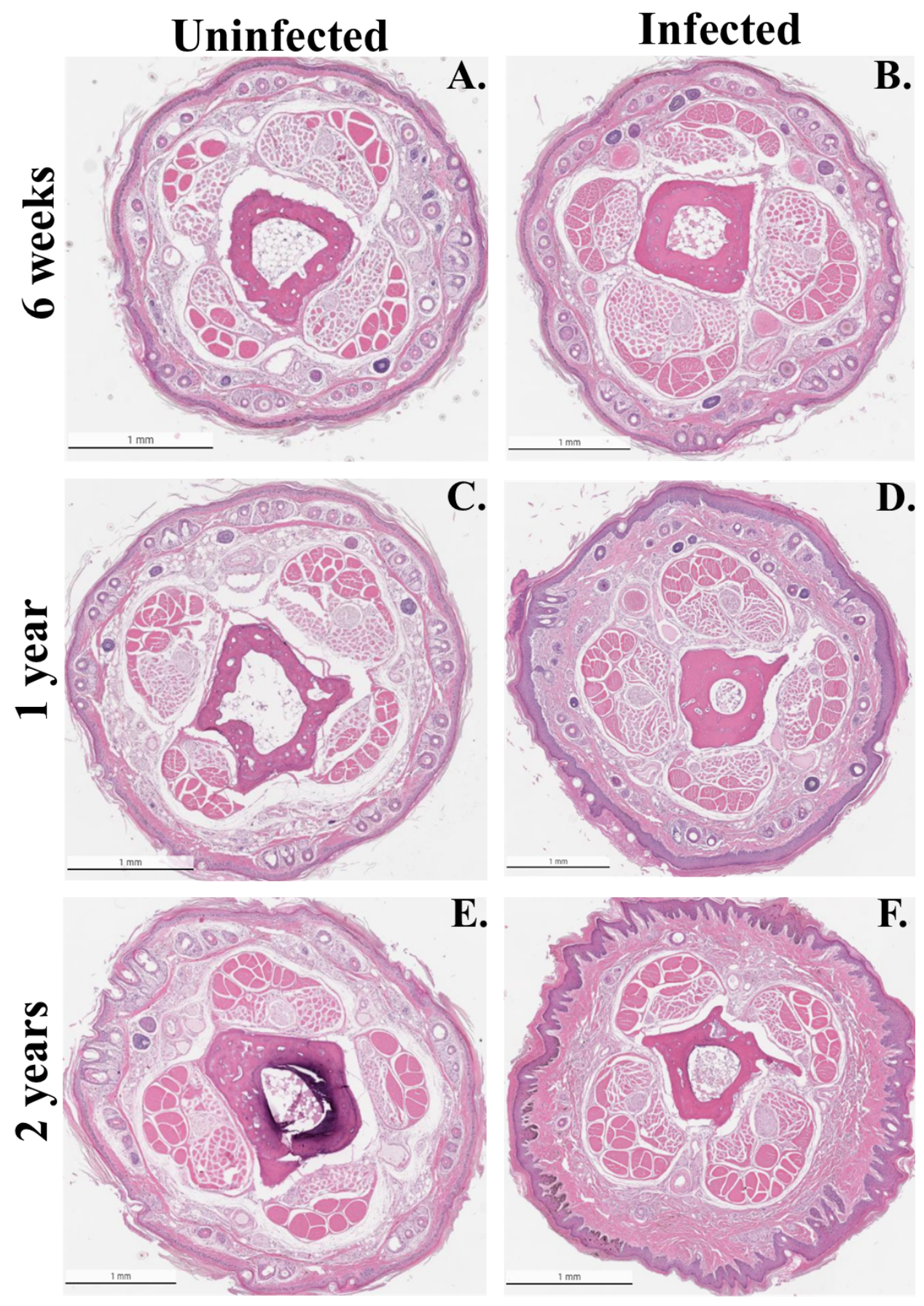

\section{Supplementary Figure 1: Histopathology of tail cross sections by age.}

Representative images of entire tail cross sections from mice infected with $B$. burgdorferi at ages of 6 weeks (B), 1 year (D) or 2 years (F) that sustained an acute infection for 2 months.

Respective age-matched, uninfected mice given vehicle controls are shown for comparison (A, C, E). Scale bars are equivalent to $1 \mathrm{~mm}$. 


\section{Internal vs External Tail Pathology}

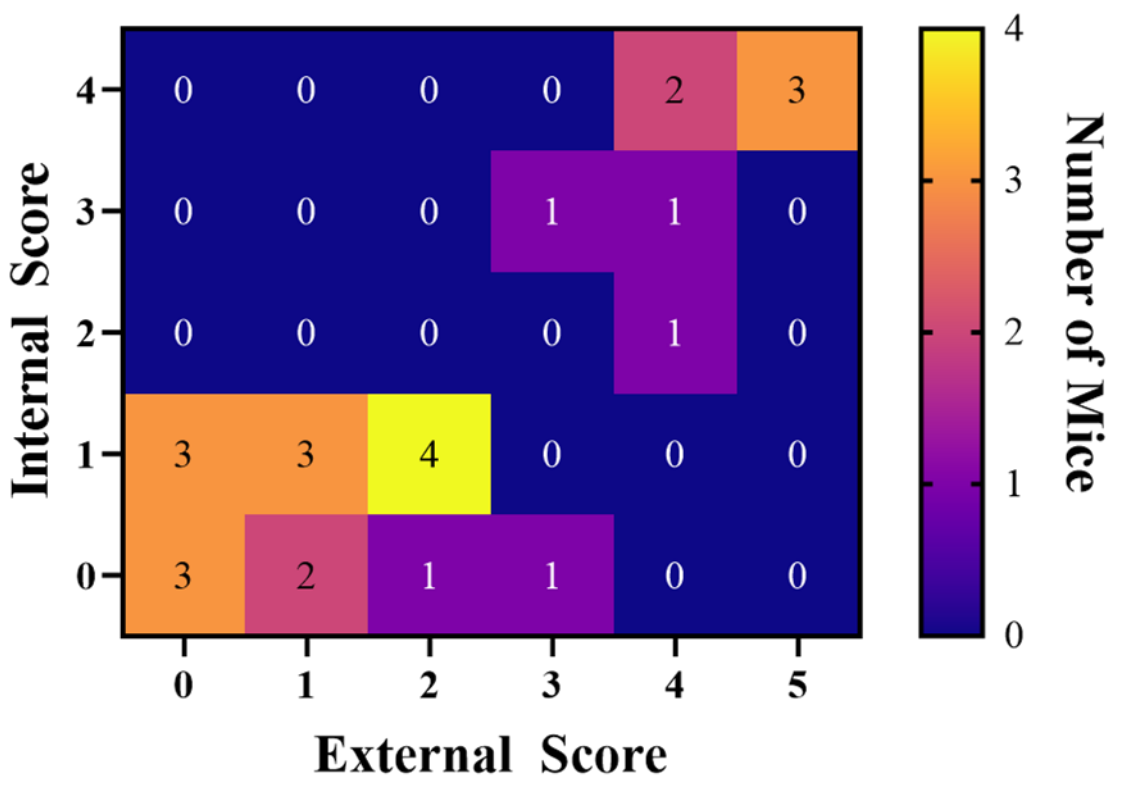

\section{Correlation Matrix of Mouse Tail Scores}

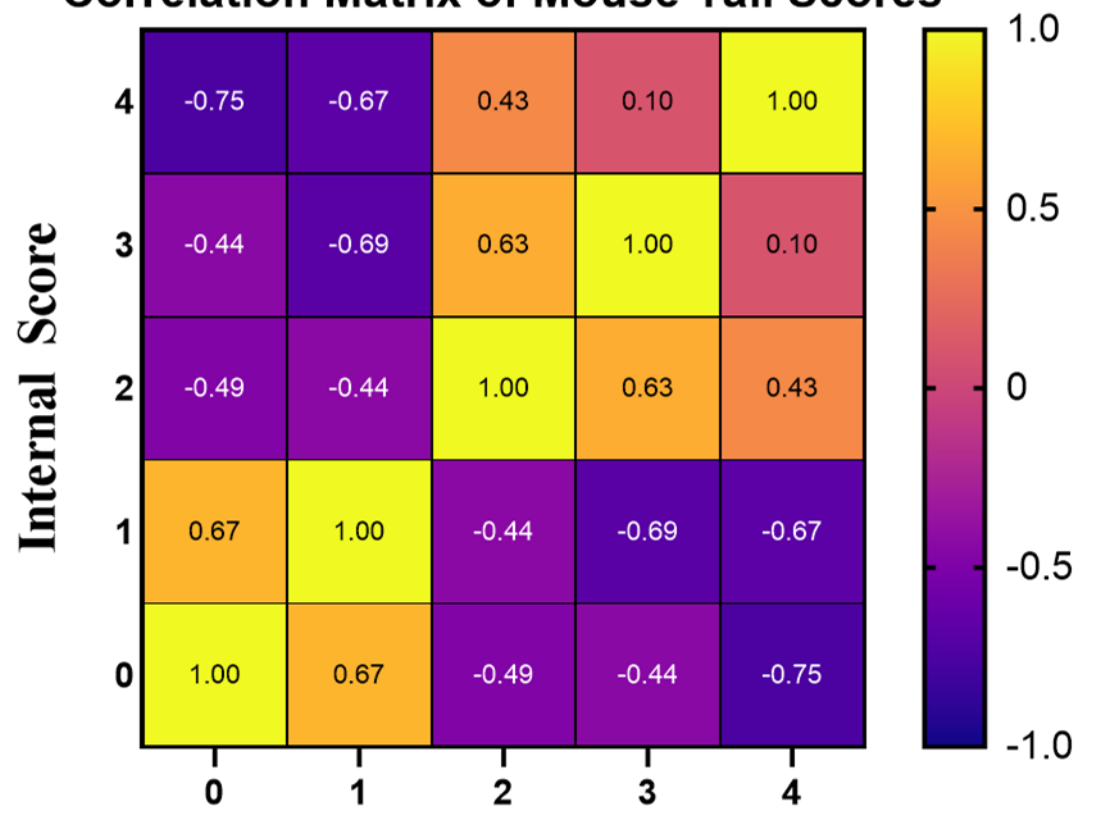

External Score

Supplementary Figure 2. Correlation of internal and external scores of atopic dermatitis.

Heat map showing number of mice with various degrees of $\mathrm{AD}$ pathology of the tail by summation of internal pathology scores plotted against external pathology scores. Dataset includes 6 week, 1 year, and 2 year old mice that sustained an acute infection of $B$. burgdorferi for 2 months, along with their age-matched uninfected controls. 


\section{REFERENCES}

1. Steere AC, Strle F, Wormser GP, Hu LT, Branda JA, Hovius JW, Li X, Mead PS. Lyme borreliosis. Nat Rev Dis Primers. 2016 Dec 15;2:16090. doi: 10.1038/nrdp.2016.90.

Erratum in: Nat Rev Dis Primers. 2017 Aug 03;3:17062. PMID: 27976670; PMCID: PMC5539539.

2. Centers for Disease Control and Prevention. (2021, April 29). Data and surveillance. Centers for Disease Control and Prevention. Retrieved October 5, 2021, from https://www.cdc.gov/lyme/datasurveillance/index.html.

3. Wilson TC, Legler A, Madison KC, Fairley JA, Swick BL. Erythema migrans: a spectrum of histopathologic changes. Am J Dermatopathol. 2012;34(8):834-837. doi:10.1097/DAD.0b013e31825879be

4. Goddard J. Not All Erythema Migrans Lesions Are Lyme Disease. Am J Med. 2017;130(2):231-233. doi:10.1016/j.amjmed.2016.08.020

5. Vasudevan B, Chatterjee M. Lyme borreliosis and skin. Indian J Dermatol. 2013;58(3):167-174. doi:10.4103/0019-5154.110822

6. Moniuszko-Malinowska A, Czupryna P, Dunaj J, Pancewicz S, Garkowski A, Kondrusik M, Grygorczuk S, Zajkowska J. Acrodermatitis chronica atrophicans: various faces of the late form of Lyme borreliosis. Postepy Dermatol Alergol. 2018 Oct;35(5):490-494. doi: 10.5114/ada.2018.77240. Epub 2018 Jul 19. PMID: 30429707; PMCID: PMC6232541.

7. Barthold SW, Beck DS, Hansen GM, Terwilliger GA, Moody KD. Lyme borreliosis in selected strains and ages of laboratory mice. J Infect Dis. 1990 Jul;162(1):133-8. doi: 10.1093/infdis/162.1.133. PMID: 2141344.

8. Barthold SW, de Souza MS, Janotka JL, Smith AL, Persing DH. Chronic Lyme borreliosis in the laboratory mouse. Am J Pathol. 1993;143(3):959-971.

9. Yang L, Weis JH, Eichwald E, Kolbert CP, Persing DH, Weis JJ. Heritable susceptibility to severe Borrelia burgdorferi-induced arthritis is dominant and is associated with persistence of large numbers of spirochetes in tissues. Infect Immun. 1994 Feb;62(2):492-500. doi: 10.1128/iai.62.2.492-500.1994. PMID: 8300208; PMCID: PMC186134.

10. Panzer R, Blobel C, Fölster-Holst R, Proksch E. TLR2 and TLR4 expression in atopic dermatitis, contact dermatitis and psoriasis. Exp Dermatol. 2014;23(5):364-366. doi:10.1111/exd.12383

11. Lin L, Xie M, Chen X, Yu Y, Liu Y, Lei K, Wang D, Zeng J, Zhou J, Zhang L, Zuo D, Sun L. Toll-like receptor 4 attenuates a murine model of atopic dermatitis through inhibition of langerin-positive DCs migration. Exp Dermatol. 2018 Sep;27(9):1015-1022. doi: 10.1111/exd.13698. Epub 2018 Jul 20. PMID: 29851146.

12. Tharmarajah G, Eckhard U, Jain F, Marino G, Prudova A, Urtatiz O, Fuchs H, de Angelis MH, Overall CM, Van Raamsdonk CD. Melanocyte development in the mouse tail epidermis requires the Adamts9 metalloproteinase. Pigment Cell Melanoma Res. 2018 Nov;31(6):693-707. doi: 10.1111/pcmr.12711. Epub 2018 Jun 5. PMID: 29781574.

13. Bladon PT, Taylor M, Wood EJ, Cunliffe WJ. Effect of crude coal tar in the mouse-tail model of psoriasis. Arch Dermatol Res. 1985;277(2):121-5. doi: 10.1007/BF00414109. PMID: 2580494. 
14. Weidinger S, Beck LA, Bieber T, Kabashima K, Irvine AD. Atopic dermatitis. Nat Rev Dis Primers. 2018;4(1):1. Published 2018 Jun 21. doi:10.1038/s41572-018-0001-z -

15. Dainichi, T., Kitoh, A., Otsuka, A., Nakajima, S., Nomura, T., Kaplan, D. H., \& Kabashima, K. (2018). The epithelial immune microenvironment (EIME) in atopic dermatitis and psoriasis. Nature immunology, 19(12), 1286-1298. https://doi.org/10.1038/s41590-018-0256-2

16. Tsoi LC, Rodriguez E, Stölzl D, Wehkamp U, Sun J, Gerdes S, Sarkar MK, Hübenthal M, Zeng C, Uppala R, Xing X, Thielking F, Billi AC, Swindell WR, Shefler A, Chen J, Patrick MT, Harms PW, Kahlenberg JM, Perez White BE, Maverakis E, Gudjonsson JE, Weidinger S. Progression of acute-to-chronic atopic dermatitis is associated with quantitative rather than qualitative changes in cytokine responses. J Allergy Clin Immunol. 2020 May;145(5):1406-1415. doi: 10.1016/j.jaci.2019.11.047. Epub 2019 Dec 28. PMID: 31891686; PMCID: PMC7214216.

17. Saunders SP, Goh CS, Brown SJ, Palmer CN, Porter RM, Cole C, Campbell LE, Gierlinski M, Barton GJ, Schneider G, Balmain A, Prescott AR, Weidinger S, Baurecht H, Kabesch M, Gieger C, Lee YA, Tavendale R, Mukhopadhyay S, Turner SW, Madhok VB, Sullivan FM, Relton C, Burn J, Meggitt S, Smith CH, Allen MA, Barker JN, Reynolds NJ, Cordell HJ, Irvine AD, McLean WH, Sandilands A, Fallon PG. Tmem79/Matt is the matted mouse gene and is a predisposing gene for atopic dermatitis in human subjects. J Allergy Clin Immunol. 2013 Nov;132(5):1121-9. doi: 10.1016/j.jaci.2013.08.046. Epub 2013 Sep 29. Erratum in: J Allergy Clin Immunol. 2015 Dec;136(6):1710. PMID: 24084074; PMCID: PMC3834151.

18. Morais KL, Miyamoto D, Maruta CW, Aoki V. Diagnostic approach of eosinophilic spongiosis. An Bras Dermatol 2019; 94: 724-728.

19. Singh B, Shinagawa K, Taube C, Gelfand EW, Pabst R. Strain-specific differences in perivascular inflammation in lungs in two murine models of allergic airway inflammation. Clin Exp Immunol. 2005;141(2):223-229. doi:10.1111/j.1365-2249.2005.02841.x

20. Alsaad KO, Ghazarian D. My approach to superficial inflammatory dermatoses. J Clin Pathol. 2005;58(12):1233-1241. doi:10.1136/jcp.2005.027151

21. Paivandy A, Pejler G. Novel Strategies to Target Mast Cells in Disease. J Innate Immun. 2021;13(3):131-147. doi: 10.1159/000513582. Epub 2021 Feb 12. PMID: 33582673; PMCID: PMC8138242.

22. Oteo JA, Backenson PB, del Mar Vitutia M, García Moncó JC, Rodríguez I, Escudero R, Anda P. Use of the $\mathrm{C} 3 \mathrm{H} / \mathrm{He}$ Lyme disease mouse model for the recovery of a Spanish isolate of Borrelia garinii from erythema migrans lesions. Res Microbiol. 1998 Jan;149(1):39-46. doi: 10.1016/s0923-2508(97)83622-4. PMID: 9766208.

23. Casselli T, Divan A, Vomhof-DeKrey EE, Tourand Y, Pecoraro HL, Brissette CA. A murine model of Lyme disease demonstrates that Borrelia burgdorferi colonizes the dura mater and induces inflammation in the central nervous system. PLoS Pathog. $2021 \mathrm{Feb}$ 1;17(2):e1009256. doi: 10.1371/journal.ppat.1009256. PMID: 33524035; PMCID: PMC7877756.

24. Moriarty, T. J., Norman, M. U., Colarusso, P., Bankhead, T., Kubes, P., \& Chaconas, G. (2008). Real-time high resolution 3D imaging of the lyme disease spirochete adhering to 
and escaping from the vasculature of a living host. PLoS pathogens, 4(6), e1000090. https://doi.org/10.1371/journal.ppat.1000090

25. Mecklenburg L, Kusewitt D, Kolly C, Treumann S, Adams ET, Diegel K, Yamate J, Kaufmann W, Müller S, Danilenko D, Bradley A. Proliferative and non-proliferative lesions of the rat and mouse integument. J Toxicol Pathol. 2013;26(3 Suppl):27S-57S. doi: 10.1293/tox.26.27S. PMID: 25035577; PMCID: PMC4091526.

26. Weyand CM, Goronzy JJ. Aging of the Immune System. Mechanisms and Therapeutic Targets. Ann Am Thorac Soc. 2016 Dec;13 Suppl 5(Suppl 5):S422-S428. doi: 10.1513/AnnalsATS.201602-095AW. PMID: 28005419; PMCID: PMC5291468.

27. Cayce, K. A. , McMichael, A. J. \& Feldman, S. R. (2004). Hyperpigmentation: An Overview Of the Common Afflictions. Dermatology Nursing, 16 (5), 401-406.

28. El Ansari YS, Kanagaratham C, Oettgen HC. Mast Cells as Regulators of Adaptive Immune Responses in Food Allergy. Yale J Biol Med. 2020 Dec 29;93(5):711-718. PMID: 33380933; PMCID: PMC7757069.

29. Talkington J, Nickell SP. Borrelia burgdorferi spirochetes induce mast cell activation and cytokine release. Infect Immun. 1999 Mar;67(3):1107-15. doi: 10.1128/IAI.67.3.1107-1115.1999. PMID: 10024550; PMCID: PMC96436.

30. Barkaway A, Rolas L, Joulia R, Bodkin J, Lenn T, Owen-Woods C, Reglero-Real N, Stein M, Vázquez-Martínez L, Girbl T, Poston RN, Golding M, Saleeb RS, Thiriot A, von Andrian UH, Duchene J, Voisin MB, Bishop CL, Voehringer D, Roers A, Rot A, Lämmermann T, Nourshargh S. Age-related changes in the local milieu of inflamed tissues cause aberrant neutrophil trafficking and subsequent remote organ damage. Immunity. 2021 Jul 13;54(7):1494-1510.e7. doi: 10.1016/j.immuni.2021.04.025. Epub 2021 May 24. PMID: 34033752; PMCID: PMC8284598.

31. Preac Mursic V, Patsouris E, Wilske B, Reinhardt S, Gross B, Mehraein P. Persistence of Borrelia burgdorferi and histopathological alterations in experimentally infected animals. A comparison with histopathological findings in human Lyme disease. Infection. 1990 Nov-Dec;18(6):332-41. doi: 10.1007/BF01646399. PMID: 2076905.

32. Zawada SG, von Fricken ME, Weppelmann TA, Sikaroodi M, Gillevet PM. Optimization of tissue sampling for Borrelia burgdorferi in white-footed mice (Peromyscus leucopus). PLoS One. 2020 Jan 24;15(1):e0226798. doi: 10.1371/journal.pone.0226798. PMID: 31978068 ; PMCID: PMC6980393. 